\title{
Comparing car-sharing schemes in Switzerland User groups and usage patterns
}

\section{Conference Paper}

Author(s):

Becker, Henrik; Ciari, Francesco; Axhausen, Kay W. (1)

Publication date:

2016

Permanent link:

https://doi.org/10.3929/ethz-b-000102869

Rights / license:

In Copyright - Non-Commercial Use Permitted 
1 Comparing Car-Sharing Schemes in Switzerland: User Groups and Usage Patterns

2 Date of submission: 2015-07-31

3

Henrik Becker, Corresponding Author

Institute for Transport Planning and Systems, ETH Zurich,

Stefano-Franscini-Platz 5

CH-8093 Zurich

phone: +41-44-633 6529

fax: +41-44-633 1057

henrik.becker@ivt.baug.ethz.ch

5

Francesco Ciari

Institute for Transport Planning and Systems, ETH Zurich,

Stefano-Franscini-Platz 5

CH-8093 Zurich

phone: +41-44-633 7165

fax: +41-44-633 1057

ciari@ivt.baug.ethz.ch

Kay W. Axhausen

Institute for Transport Planning and Systems, ETH Zurich,

Stefano-Franscini-Platz 5

CH-8093 Zurich

phone: +41-44-633 3943

fax: +41-44-633 1057

axhausen@ivt.baug.ethz.ch

9 Words: 5694 words +3 figures +4 tables $=7444$ word equivalents 


\begin{abstract}
1 ABSTRACT
2 Free-floating car-sharing schemes operate without fixed car-sharing stations, ahead reservations 3 or return-trip requirements. Providing fast and convenient motorization, they attract both public 4 transport users and (former) car-owners. Therefore, the environmental impact of these novel 5 systems is hard to estimate. This research uses a difference in difference approach to estimate 6 the impact of free-floating car-sharing on its members' travel behaviour. Data is collected using 7 member surveys combined with a smartphone-based GPS-tracking solution. The results can 8 be directly compared with both a station-based round-trip car-sharing service operating in the 9 same city and a random control group. The findings suggest, that free-floating car-sharing has a 10 similar socio-demographic customer potential as station-based round-trip car-sharing. However, 11 free-floating car-sharing has more active members and is employed for a broader variety of 12 uses. Moreover, the results suggest, that it reduces car-ownership on a level comparable to 13 station-based round-trip car-sharing.
\end{abstract}




\section{INTRODUCTION}

Since its first implementation in the late 1940s, car-sharing has for a very long time been a niche service unable to attract a substantial share of the urban population. The status was due to both the inflexibility of the car-sharing systems themselves and the social importance of car-ownership. In recent years, the game has changed: User-friendly and flexible systems have entered the market and a social trend promoting sharing over ownership supports their adoption.

The latest addition to the car-sharing market has been free-floating car-sharing. Instead of relying on designated car-sharing stations it allows customers to pick-up and drop-off the vehicle anywhere within a city-wide service area. By this, it removes the obstacles of stationbased round-trip car-sharing (from now on referred to as station-based car-sharing) such as the requirement of ahead reservations and the restriction to round-trip use only.

Given these structural differences between the two service types, knowledge about user groups and environmental effects of station-based car-sharing may not be directly transferrable to free-floating car-sharing. In oder to close this research gap, a few empirical studies on freefloating car-sharing have already identified major user groups and their motivations. Moreover, dominant usage patterns as well as environmental implications (1, 2) were investigated. However, the environmental effects of the new service proved more difficult to assess. Offering a convenient and fast new form of urban mobility, free-floating car-sharing attracts both (former) car owners and transit users. Therefore, it is still unclear how its growing diffusion affects overall travel behavior (3).

The introduction of the novel free-floating car-sharing service in Basel for the first time allows an investigation of the usage and impacts of the different forms of car-sharing in the Swiss context. Using empirical data this research contributes to a better understanding of the environmental implications of new free-floating car-sharing by studying travel patterns and user groups. Moreover, the collected data for the first time allows a direct comparison between two different car-sharing systems operating in the same city.

The remainder of this paper is structured as follows: Section 2 provides a short overview of the relevant scientific literature, Section 3 describes the methodology of this study including details about the response behaviour. The results of this study are then presented in Section 5. Section 6 concludes with an outlook onto the next steps of this research.

\section{BACKGROUND}

\section{Free-Floating Carsharing}

The roots of today's more and more successful car-sharing systems can be traced back to the late 1940s, when the first systems were conceived to share a useful, yet expensive asset - the car. As the first implementation of a car-sharing service, the Sefage program in Zurich was established in 1948 (4). Systems in other European cities followed. However, in an era of fast and ever-cheaper private motorization beginning in the 1950s, car-sharing lacked attractiveness. Only in the early 1990s rising fuel prices and a congested road network built the path for a successful revival of the idea of car-sharing. Technology has been key to unlock this new potential by providing user-friendly systems and efficient allocation strategies and has even led to the development of new forms such as peer-to-peer car-sharing or free-floating car-sharing.

The scientific literature about car-sharing has grown in scope and size in recent years as has the diffusion of the service itself. There already exists a large corpus of literature that deals with 
many of its different aspects.

The overwhelming majority of the literature on car-sharing has been written in the last 20 years (5) and mainly covered traditional station-based car-sharing services. The research has produced agreement on several issues: For station-based car-sharing it is widely accepted that the most suitable markets are dense urban areas with a good public transport supply $(6,7)$ and that the prototype user is relatively young, affluent and well educated. Regarding the impact of car-sharing on the transportation system researchers were able to confirm several positive impacts like less vehicle travel and lower emissions $(8)$ as well as reducing the need for parking $(5,9)$.

Predictions concerning car-sharing demand and diffusion levels, however, proved overoptimistic: For example an early study in Austria estimating a market potential of 9\% (10) as well as a Swiss study predicting a potential of 600000 customers for the service of Mobility Switzerland (11) were both off by more than a factor of five.

Only recently, research has extended its scope to the newest forms of car-sharing such as free-floating car-sharing and their environmental impact. Whilst early studies expected a significant reduction in car ownership and $\mathrm{CO}_{2}$ emissions (12) due to free-floating car-sharing, the actual impact seems to be more complex as non-car-owners reduce bike, walk and public transit trips, but start to use a (shared) car instead (13). First reports from municipalities having introduced free-floating car-sharing are also ambivalent. For example, a first study after one year of operation of car2go, a free-floating car-sharing service, in Seattle found the following inconclusive results: Whilst 39\% of car2go members had at least considered giving up a car and a third of the members were traveling fewer miles with their private car, nearly half reported to ride transit less frequently and two thirds have not changed the amount vehicle miles travelled with their private car despite despite their (additional) car2go use (3).

A similar pattern has also been observed in the case of traditional car-sharing services, where slight increases of vehicle miles travelled (VMT) by the majority of customers were more than balanced by substantial decreases in VMT by the remainder of the customers (14) resulting in a significantly positive overall impact.

But it is not clear, whether this also holds true for free-floating car-sharing. A recent British study directly comparing point-to-point car-sharing to round-trip car-sharing, confirmed, that the structural differences between the services imply different usage patterns. In particular, they found that round-trip car-sharing has a far more positive impact on the transport system as it is used to complement public transit, whereas point-to-point car-sharing is used in parallel to public transit and therefore has a questionable impact on the transportation system (15). Nonetheless, point-to-point car-sharing - due to its flexibility - was found to have a substantially higher market potential.

Given their high popularity and the fact, that free-floating car-sharing services depend on local authorities to issue special parking permits, their environmental impact is of particular interest. However, it turned out, that the systems' impact on their members' travel behaviour is complex and not straighforward to determine. For example, point-to-point car-sharing lets non-car-owning members shop for groceries less frequently, visit fewer distinct food shops and spend less total time traveling for grocery shopping purposes (16). Moreover, the impact of free-floating car-sharing, is not stable, but highly dependent on weather conditions (2) or pricing structures (17). Therefore, further research is required, to investigate the usage patterns and to determine the actual environmental net impact of free floating car-sharing. 


\section{Free-floating car-sharing in Basel}

In August 2014, a free-floating car-sharing pilot program has been launched in Basel, Switzerland. 120 cars of the type VW Up have been distributed around the city. They can be located via a website or smartphone-app and reserved for up to 15 minutes. Customers have to pay a small registration fee upfront and then only pay on a per-use basis. The fare structure distinguishes between parking and driving time; customers are charged per minute. At the end of the journey, the vehicle can be parked on any public parking bay within the service area. It will then become available for other members.

Although both the station-based car-sharing service and the free-floating car-sharing service are operated by the same company, they are treated entirely separately. As a consequence, customers wishing to use both services have to register for each service separately.

\section{METHODOLOGY AND DATA}

Since August 2014, there have been two different car-sharing services operating in Basel: a new free-floating car-sharing pilot has been added, which has for decades been served by a round-trip and station-based scheme. Both services are offered by the same operator.

In order to capture the full impact of the new free-floating car-sharing service on the transportation system, a difference-in-difference approach has been chosen for this study. A panel consisting of three different participant groups are surveyed directly after the launch of the free-floating car-sharing service and again one year later. As a valid estimation of the impact of the free-floating car-sharing service requires quantitative travel behaviour data, each of the survey wave consists of both a questionnaire and a week-long travel diary.

Although people's travel behaviour may have already been influenced by the new freefloating car-sharing service when taking the first survey wave, it is impossible to identify them before they register. Moreover, (18) have shown, that the main effects of a car-sharing service occur about two years into the operation of that service. Hence, it is assumed, that due to the short time between registration and survey, no substantial changes have already occured.

The three groups considered for the survey are: members of the new free-floating car-sharing service, members of the conventional car-sharing service and driver license holders among a random sample of the local population. This way, the effect of the free-floating car-sharing service on its members can be isolated from general trends in travel behaviour.

\section{Travel Survey Methods}

As detailed above, a determination of the effect of free-floating car-sharing services requires the collection of quantitative travel behaviour data. As individual travel behaviour varies over the course of the week, a week-long travel-diary containing all the participant's trips was required. However, collecting this data using manual trip diaries may lead to imprecise and missing data (19, 20). Although GPS-loggers would allow to raise the data quality, they come with high administrative costs for the researcher (2i). A most recent alternative promising to reduce both the response burden for participants as well as the administrative effort is smartphone-based GPS-tracking (22 25). In this setup, participants simply download an app on their smartphone, which automatically tracks their daily trips using the built-in GPS-sensor.

Given the various advantages described above, a smartphone-based GPS-tracking system, Studio Mobilità (26), has been employed for this study. Although this allows only smartphone- 
holders to take part in the study, selection-bias effects can still be neglected. This is, because the study is supposed to compare the travel behaviour of free-floating car-sharing members with a control group coresponding to their socio-demographic characteristics. As the free-floating car-sharing service can only be used by smartphone-owners, non-owners are excluded by design.

\section{Recruitment and data acquisition}

In total, 1218 free-floating members, 2224 station-based members and 6000 members of the random sample were invited to take part in the study. Whilst address lists of car-sharing members were made available by the operator, surface-mail addresses for the random sample of the population were provided by the Cantonal Statistical Office of Basel-Stadt. The random sample was drawn from the local population above legal age.

The study consisted of two separate parts. The first was a survey about socio-demographic attributes as well as the participants' general mobility behavior, whereas the second part was a one-week travel diary using a smartphone-based GPS-tracker. Participants were asked to fill in the survey by the end of the week of receipt and to keep the diary the week after. Details and instructions concerning the mobility diary were given at the end of the survey.

Each of the three participant groups was provided with dedicated questionnaires. Whilst the car-sharing members were recruited via e-mail and were able to access the online-survey using personalized links, members of the control group received the survey in pencil-and-paper-format via surface mail including a reply-paid envelope. Due to company policy reasons, car-sharing members were only invited to the questionnair first. Upon completion of the questionnaire, they were automatically invited to take part in the mobility diary and were promised a 15 CHF credit on their next car-sharing bill. In contrast, members of the control group have received all the necessary information along with the questionnaire. As incentive, they were offered a $15 \mathrm{CHF}$ app-voucher in return for their full participation.

Participants were invited to take part in the study in weekly waves in calendar weeks 43 to 50 in 2014. In the last week, reminders were sent out to all those car-sharing members who had failed to answer the survey on schedule by then. Moreover, participants, who were overdue in completing their mobility diary were offered assistance. Moreover, free-floating car-sharing members having joined the service after the first survey wave were invited to take the survey in April 2015.

The response burdens of the questionaires were calculated as 178 points (free-floating members), 173 points (station-based members) and 135 (control group) (27). For an average week-long mobility diary, an additional burden of 362 points was assumed. The achieved response rates are given in Table 1 and can be compared with experiences from previous studies as given in Figure 1. As can be seen from the figure, the response rates for the questionnaires are well within the expected range. For the free-floating car-sharing members a bit higher response rate could be observed indicating a high level of identification with the service. In contrast, the response rates for members of the control groups fall off. The difference may be explained by the fact, that both the car-sharing groups were contacted on behalf of the service they were member of.

However, comparing the response rates of the diaries with earlier studies, they are found to be much lower than expected. As the participants can be regarded as pre-recruited by the questionnaires, a response rate of almost $80 \%$ would have been expected. Instead, it turned out to be substantially lower. Based on the participant feedback and the fact, that almost all 


\section{TABLE 1 Response rates per participant groups}

\begin{tabular}{lrrr}
\hline Calendar week & free-floating & station-based & control group \\
\hline Invitations sent & 1218 & 2224 & 6000 \\
\hline Surveys completed & 366 & 571 & 594 \\
with drivers license & 366 & 571 & 447 \\
Response rate of the eligible & $37.4 \%$ & $25.7 \%$ & $9.1 \%$ \\
\hline Diaries completed & 91 & 96 & 226 \\
Response rate of the eligible & $24.9 \%$ & $16.8 \%$ & $50.6 \%$ \\
\hline
\end{tabular}

dropouts during the web-based-survey took place, when participants had to confirm a data privacy declaration, the authors assume, that this drop in response rate can be attributed to data protection concerns. For the two car-sharing member groups, this data privacy effect is furthermore overlayed by a second effect, which can be attributed to the piecewise invitation strategy. For car-sharing members, information about the mobility diary and the incentive was only communicated after they had voluntarily completed the questionnaire. This left the impression, that the mobility diary was a completely separate survey, and therefore substantially increased the dropout rate. Interestingly, this effect could not be corrected by the incentive (a car-sharing credit) indicating that the offered incentive was of only limited appeal.

\section{Data quality}

Response bias was addressed using three measures: Firstly, only completed questionnaires were considered for the analysis. Secondly, responses from car-sharing members who completed the survey in less than seven minutes (a third of the average time) were excluded. Thirdly, unreasonable answers were identified on a per-question basis (e.g. year of birth before 1900).

In order to test for a selection bias, the response groups of the car-sharing members were compared to age and gender information available from the address lists. Since the gender distribution for both car-sharing samples equaled the population up to a percent, no further statistical tests were conducted for the variable gender. Concerning year of birth, a Cramér-vonMises-test (28) has been run. It was found, that the response groups are a suitable representation of their respective car-sharing member population ( $p$-value 0.05 for station-based and 0.18 for free-floating members) when shifted by three years in the age variable. This shift is due to the fact, that older members are overrepresented in the response group. However, as a shift of three years causes only small changes in a person's mobility behavior, the validity of the data is not severely affected.

For the control group only the subgroup of driver license owners is considered. Again, participants of the age group 55 to 65 years are overrepresented. Still, there is good reason to regard the response group as sufficiently representative. Also when considering the gender distribution, the response group matches the actual population of driving license holders well ( $44.5 \%$ vs. $45.5 \%$ females). 


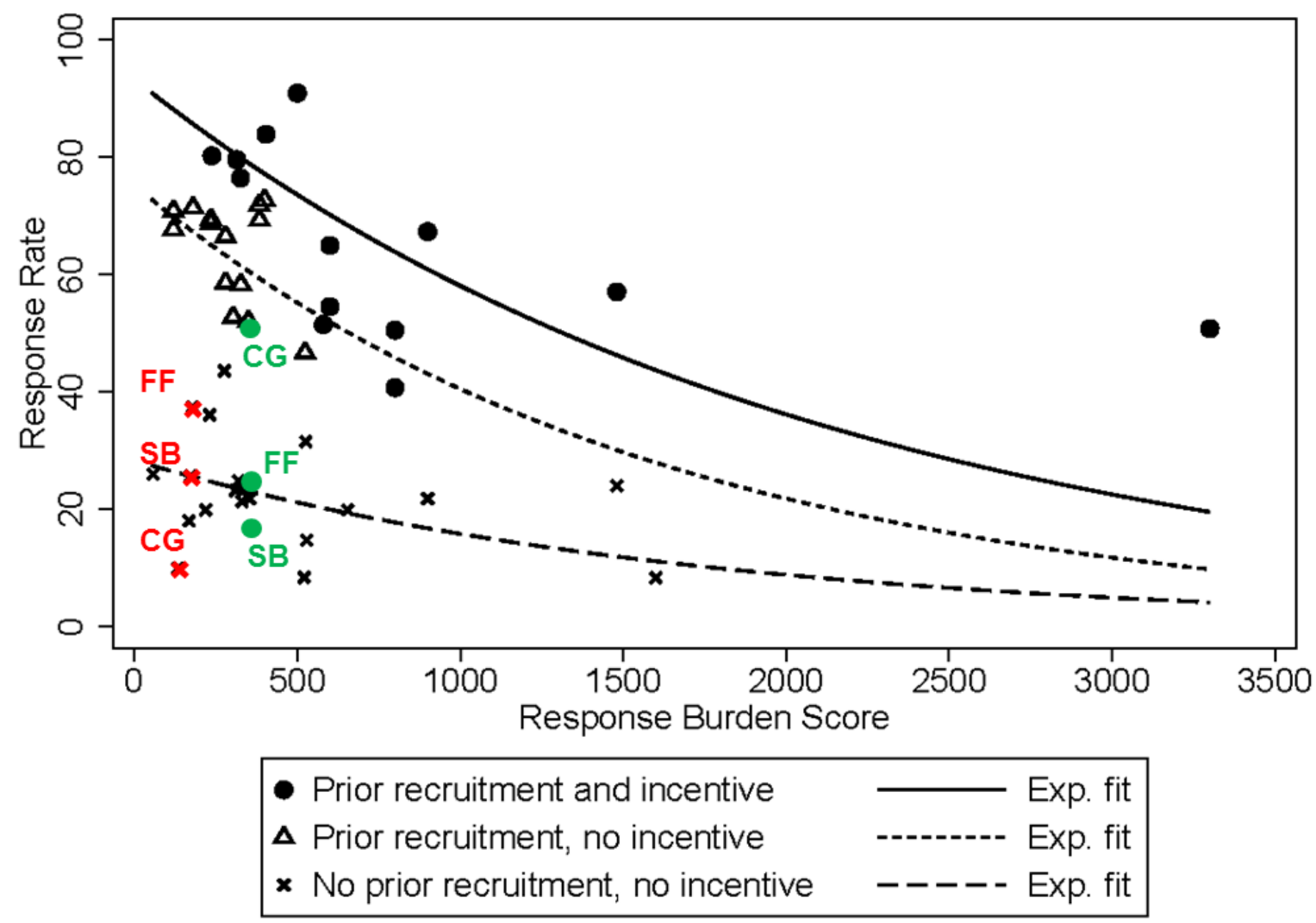

Source: (27). The response rates of the questionnaires of the three survey-groups are given as red crosses, the response rates for the questionnaires are given as green dots. FF denotes free-floating members, SB station-based members and CG control group.

\section{FIGURE 1 Response rates in comparison with other comparable studies.}

\section{SURVEY RESULTS}

2 In this section, the data of the first survey wave is analyzed. All three survey groups are treated separately, such that the properties of the free-floating car-sharing service can be compared to both the station-based car-sharing service and the control group. It is assumed, that the samples are sufficiently representative for their respective population. Although more information supporting the hypotheses of this paper was available, some of it has been (partially) withheld in order to protect the operator's commercial interest.

\section{Who uses car-sharing in Basel?}

$76.8 \%$ of the free-floating car-sharing members in Basel are male $(N=366)$ compared to $65.0 \%$ for the station-based car-sharing service $(N=571)$. Hence, men are substantially overrepresented among car-sharing members compared to their share of 55.6\% $(N=446)$ among the control group of driver license holders. This effect is strongest for free-floating car-sharing.

Moreover it is well-known from the literature, that station-based car-sharing attracts customers who are several years younger than the average of the adult population (5). Similar to 
the gender distribution described above, the average age of free-floating car-sharing members was found to be even lower than the one of the station-based car-sharing service.

Differences in the highest educational degree are also apparent. Whereas only $41.6 \%$ of the members of the control group $(N=445)$ hold a university degree, the share is distinctly higher among free-floating car-sharing members $(45.8 \%, N=360)$ and station-based car-sharing members $(51.4 \%, N=568)$. Interestingly, in this variable, station-based car-sharing is more extreme. Moreover, the free-floating car-sharing service attracts more people with a professional education (apprenticeship) with a share of $14.2 \%$ versus $9.9 \%$ for the station-based service. Also customers holding a high-school degree are more abundant among free-floating car-sharing members $(8.6 \%)$ than among station-based members $(6.3 \%)$. The latter two observations are in line with the above result of a lower average member age.

The age differences are also reflected in the employment status: Whilst $83 \%$ of the carsharing members are employed or self-employed (compared to $65 \%$ in the control group) irrespective of the kind of service, the free-floating car-sharing service is used by more students $(9.1 \%, N=364$ vs. $3.2 \%, N=567)$. In turn, the station-based car-sharing service attracts more retirees $(9.3 \%$ vs. $4.9 \%)$, although still remaining below the $25 \%$ share of retirees in the control group.

Furthermore, members of the free-floating car-sharing service tend to live in larger households with an average size of 2.47 household members $(N=312)$. This compares to an average size of 2.38 among the control group members $(N=443)$ and 2.31 among members of the station-based service $(N=571)$. The share of single-households, however, is at the level of $23 \%$ for the free-floating and control group members, but substantially higher $(30 \%)$ among station-based members. In turn, $28 \%$ of the free-floating car-sharing members live in families with children, compared to $25 \%$ among the station-based members and $23 \%$ in the control group.

Regarding their household income, free-floating car-sharing members' average is slightly above the control group and members of the station-based car-sharing slightly below. Yet, the differences in the average household incomes are not statistically significant.

A logistic regression helps to identify the socio-demographic variables significantly related to membership in a car-sharing-organization. The data was obtained from the completed questionnaires. For the two models, the responses from the control group and the respective member group were used. In both cases, a backward selection was conducted in order to obtain the best model fit. The final models are given in Table 2 . They are highly significant and indeed different for the two car-sharing systems. For example, gender and household size are irrelevant for station-based car-sharing membership, they are highly significant predictors for free-floating membership. Most interestingly, age is not significant for either service, but is captured in the different life cycle position of students, workers and retirees.

Thus, both services attract highly educated customers, especially retirees or active workers. Students, however, are less likely to be members of a station-based service. Moreover, likelihood to be a car-sharing member decreases with higher incomes and does so more strongly for free-floating car-sharing. Furthermore, free-floating car-sharing is particularly attractive for men and households with more than one adult.

When using the socio-demographic model from Table 2 to predict car-sharing membership among respondents from the control group, for both systems, a 9\% market share among the licensed population is predicted. This result agrees with former market potential estimations 


\section{TABLE 2 Logistic Regression on factors influencing Car-sharing membership}

\begin{tabular}{l|r|r}
\hline & station-based system & free-floating system \\
\hline (Intercept) & $\mathbf{0 . 2 5 0 * * *}$ & 0.014 \\
male & $(0.025)$ & $(0.040)$ \\
& - & - \\
age & - & $\mathbf{0 . 0 7 3} * * *$ \\
& - & $(0.019)$ \\
university degree & $0.030^{*}$ & $1.5 \mathrm{e}-4$ \\
& $(0.015)$ & $(7.2 \mathrm{e}-5)$ \\
household income (in CHF) & $-3.9 \mathrm{e}-6^{*}$ & 0.035 \\
& $(1.7 \mathrm{e}-6)$ & $(0.020)$ \\
\# adults in household & - & $\mathbf{- 1 . 1 e - 5 * * *}$ \\
& - & $(2.2 \mathrm{e}-6)$ \\
student & $\mathbf{0 . 0 4 7} * * *$ \\
& $(0.012)$ \\
retiree & $(0.024)$ & $4.6 \mathrm{e}-4$ \\
& $\mathbf{0 . 6 6 0 * * *}$ & $(3.0 \mathrm{e}-2)$ \\
(self-)employed & $(0.036)$ & $\mathbf{0 . 6 1 0} * * *$ \\
& $\mathbf{0 . 7 5 0 * * *}$ & $(0.065)$ \\
& $(0.024)$ & $\mathbf{0 . 8 9 0} * * *$ \\
& $N=1014$ & $(0.032)$ \\
\hline
\end{tabular}

First row shows parameter estimates, second row shows standard error.

Significance codes: $* * * 0, * * 0.001, * 0.01 ; "-"=$ not applicable

(10, 11) for station-based car-sharing, which have, however, proven to be overoptimistic. It remains to be seen, whether free-floating car-sharing systems will be able to fully realize the predicted potential.

\section{Do car-sharing members show a different travel behaviour?}

Already on first sight, car-sharing member households are much less car-oriented compared to households from the control group. For example, the share of GA travelcard holders (allowing for year-long free public transport use throughout Switzerland) is almost twice as high among freefloating (28\%) and station-based (30\%) car-sharing members than in the control group (17\%). Given, that the average GA travelcard holdership in Basel according to the last microcensus was $8.3 \pm 5.2 \%$ in 2010 (29), the survey results indicate a bias in the response group.

Moreover, station-based car-sharing households are $84 \%$ car-free compared to $58 \%$ for free-floating member households and $32 \%$ in the control group. In turn car-sharing households own more bikes.

Such strategic mobility decisions as described above have manifold implications on the individual travel behaviour. As an example, Figure 2 shows the mode distribution for all trips 


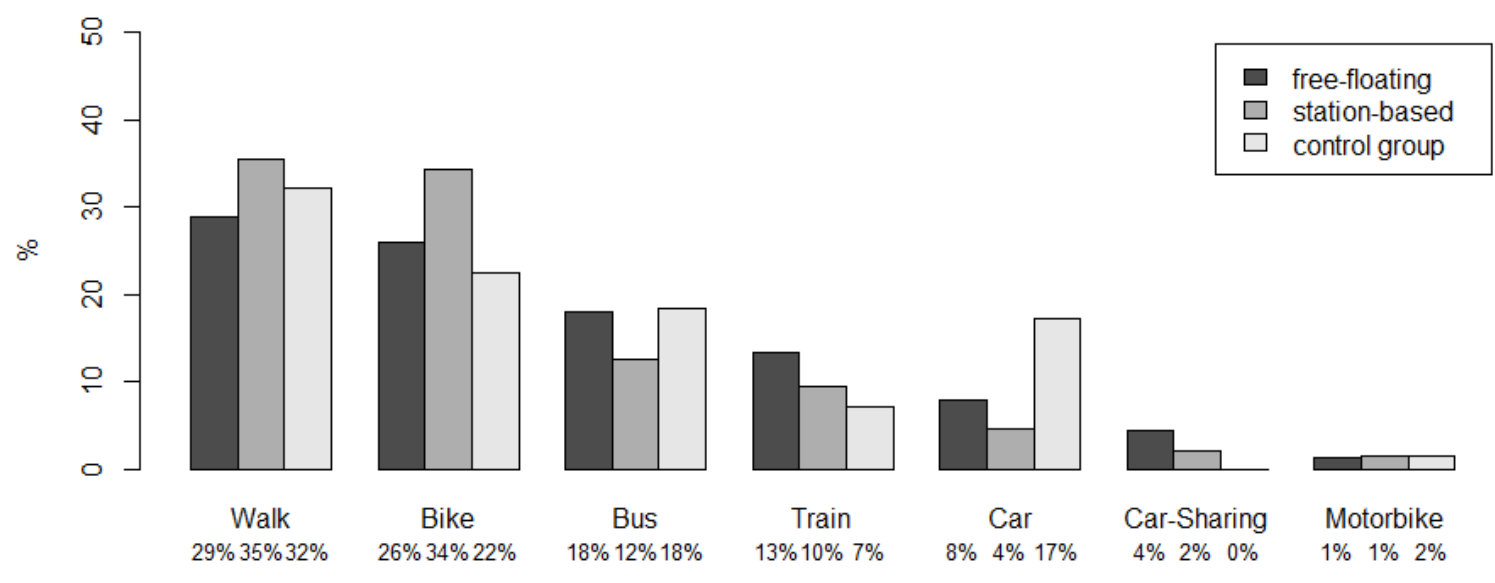

FIGURE 2 Modal split on trip level.

being recorded in the mobility diaries by group. Indeed, the different equipment with mobility tools is mirrored in the mode choice: station-based car-sharing members, who own the fewest cars, but the most bikes, use slow modes for most of their trips. Members of the free-floating car-sharing service, however, rely more on public transportation and also use car-sharing more frequently.

Weighting the modal split by travel time allows to further investigate how many different modes the respondents acitvely use for their daily travel behaviour. A means to quantify this flexibility in mode choice is the multimodality index (MMI) (30). The concept of the MMI has its origin in the Herfindahl-Hirschmann-Index (31), a measure for concentration in economics. As in (30), the MMI is calculated by

$$
\mathrm{MMI}=\left(1-\sum_{i}\left(\frac{t_{i}}{\sum_{j} t_{j}}\right)^{2}\right) \cdot \frac{n}{n-1}
$$

Whilst the first part of the formula directly stems from the Herfindahl-Hirschmann-Index with $t_{i}$ being the travel time for a single mode, the fraction at the end normalizes the MMI to a $[0,1]$ scale with $n$ the number of available alternatives. On this scale, values closer to one indicate an equal distribution of travel time among the different modes, whereas smaller values hint at monomodality.

Interestingly, the MMI has no significant variations between the three survey groups. In fact, it is largest for the control group $\left(\mathrm{MMI}_{C G}=0.71 \pm 0.30\right)$ and lowest for members of the station-based car-sharing service $\left(\mathrm{MMI}_{S B}=0.63 \pm 0.26\right)$. The relation can be explained by above observation, that car-sharing members rarely use cars, whereas car-users are more likely to also walk, bike or use public transport.

However, the average MMI of the different survey groups may have been biased by their different socio-demographic composition (c.f. Table 2). In order to isolate the actual effect of car-sharing membership on the MMI, a treatment effect model based on a two-step Heckman correction (32) has been estimated. In the first step of this procedure, a probit model is used 
1 to predict car-sharing membership for the individual respondents. Thereafter, the predicted membership enters the main regression equation as an endogeneous variable. This model is preferred over a simple regression model as it accounts for the endogeneity of car-sharing membership.

The estimated model confirms the above finding, that car-sharing members do not show a significantly different multimodal behaviour compared to the control group.

In the next step, the relation between car-sharing membership and car-ownership and -usage is investigated further. Given the substantial socio-demographic disparities between the control group an the car-sharing member groups, it is again necessary to estimate a treatment effect model.

Taking into account the large differences between weekday and weekend travel behaviour, the model has been estimated for weekday-trips only. The results are presented in Table 3 In both cases, the correlation of the error terms $\rho$ is significant, hence, the estimation can be assumed to be unbiased. In the first model, the number of cars is estimated depending on sociodemographic variables and GA-travelcard ownership and car-sharing membership. Whereas household income has a significant positive influence on car ownership, both GA travelcard holdership and car-sharing membership have a significant negative effect. All other attributes being equal, households of free-floating car-sharing members own 0.82 cars less. Households of station-based members even own 0.91 cars less than non-members. Therefore, the statistical effect of car-sharing membership is four times stronger as GA travelcard holdership.

TABLE 3 Treatment Effect Model for Car Ownership and Usage

\begin{tabular}{|c|c|c|c|c|}
\hline & \multicolumn{2}{|c|}{ \# cars in household } & \multicolumn{2}{|c|}{ daily $\mathrm{km}$ travelled by car $(\log )$} \\
\hline \multicolumn{5}{|l|}{ main regression } \\
\hline \multirow[t]{2}{*}{ household income (in $\mathrm{kCHF}$ ) } & $\mathbf{0 . 0 3 9} * * *$ & $\mathbf{0 . 0 3 4} * * *$ & 0.047 & $0.060 *$ \\
\hline & $(0.01)$ & $(0.01)$ & $(0.03)$ & $(0.03)$ \\
\hline \multirow[t]{2}{*}{ \# minors in household } & $0.089 * *$ & $0.100 * *$ & -0.198 & -0.122 \\
\hline & $(0.04)$ & $(0.04)$ & $(0.16)$ & $(0.15)$ \\
\hline \multirow[t]{2}{*}{ age } & -0.000 & 0.002 & $-0.016^{*}$ & -0.013 \\
\hline & $(0.00)$ & $(0.00)$ & $(0.01)$ & $(0.01)$ \\
\hline \multirow{2}{*}{ GA travelcard } & $-0.220 * * *$ & $-0.195 * * *$ & $-0.605^{*}$ & $-0.604 * *$ \\
\hline & $(0.07)$ & $(0.07)$ & $(0.31)$ & $(0.28)$ \\
\hline \multirow[t]{2}{*}{ \# bikes in household } & -0.005 & -0.010 & - & - \\
\hline & $(0.02)$ & $(0.02)$ & - & - \\
\hline \multirow[t]{2}{*}{ free-floating member } & $-\mathbf{0 . 8 1 5} * * *$ & - & $1.278^{* *}$ & - \\
\hline & $(0.11)$ & - & $(0.62)$ & - \\
\hline \multirow[t]{2}{*}{ station-based member } & - & $-0.906 * * *$ & - & $2.930 * * *$ \\
\hline & - & $(0.11)$ & - & $(0.53)$ \\
\hline \multirow[t]{2}{*}{ male } & - & - & 0.135 & 0.317 \\
\hline & - & - & $(0.28)$ & $(0.24)$ \\
\hline \multirow[t]{2}{*}{ occupation: student } & - & - & $0.693 *$ & $0.815^{*}$ \\
\hline & - & - & $(0.41)$ & $(0.42)$ \\
\hline \multirow[t]{2}{*}{ occupation: retiree } & - & - & 0.262 & -1.033 \\
\hline & - & - & $(0.76)$ & $(0.81)$ \\
\hline occupation: worker & - & - & 0.315 & -0.327 \\
\hline
\end{tabular}




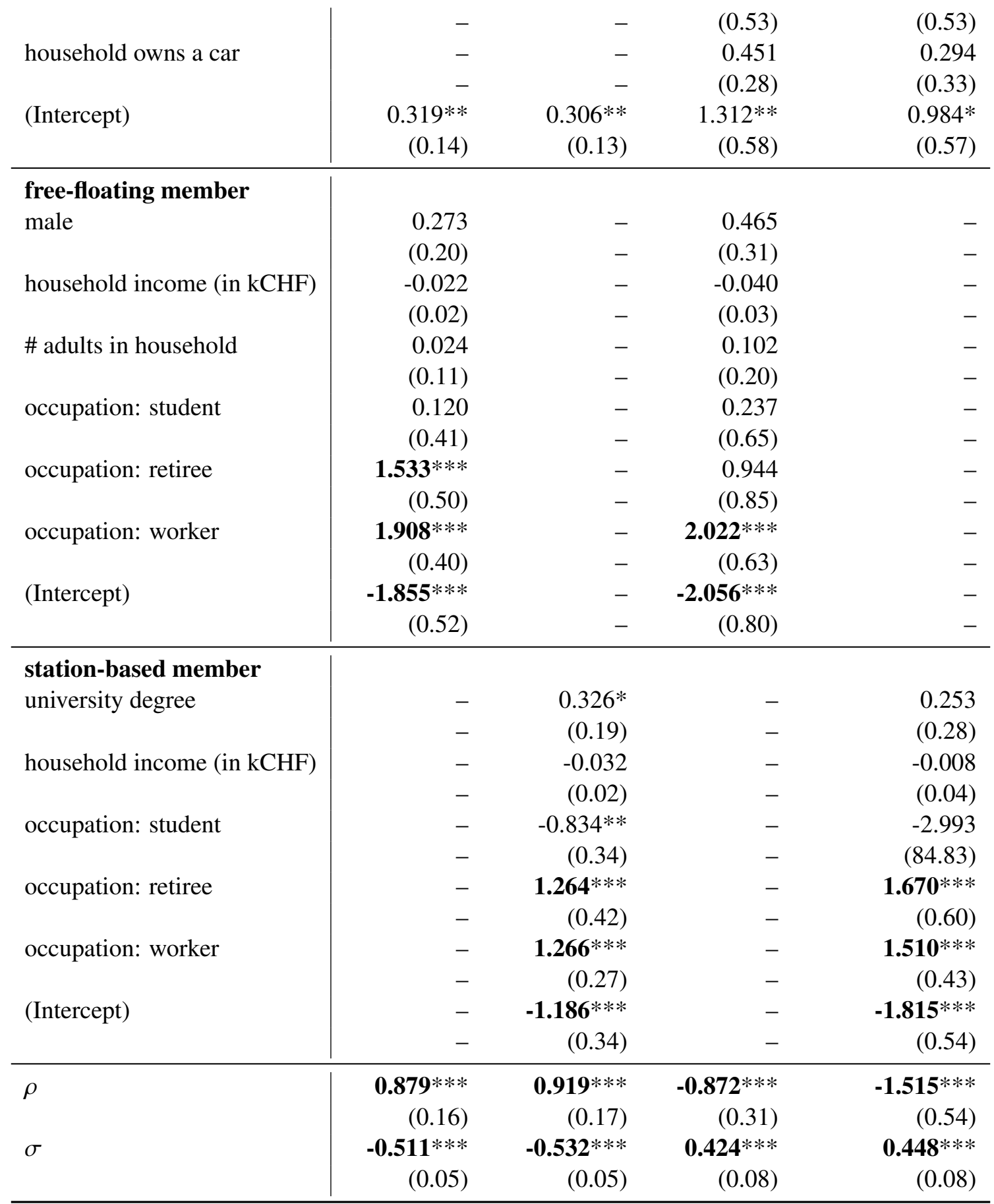

First row shows parameter estimates, second row shows standard error.

Significance codes: $* * * 0, * * 0.001, * 0.01 ; "-"=$ not applicable

However, the effect is reversed when looking at the average daily kilometers travelled in a car (as driver or passenger, with a private or shared car). Here, car-sharing membership has a significant positive correlation with the amount of weekday kilometers driven by car. Hence, all other factors being equal, car-sharing members are found to travel higher average weekday distances in a car.

In consequence, members of both car-sharing schemes were found to own almost one car less than their peers. This also explains the observation, that car-sharing members use slow 


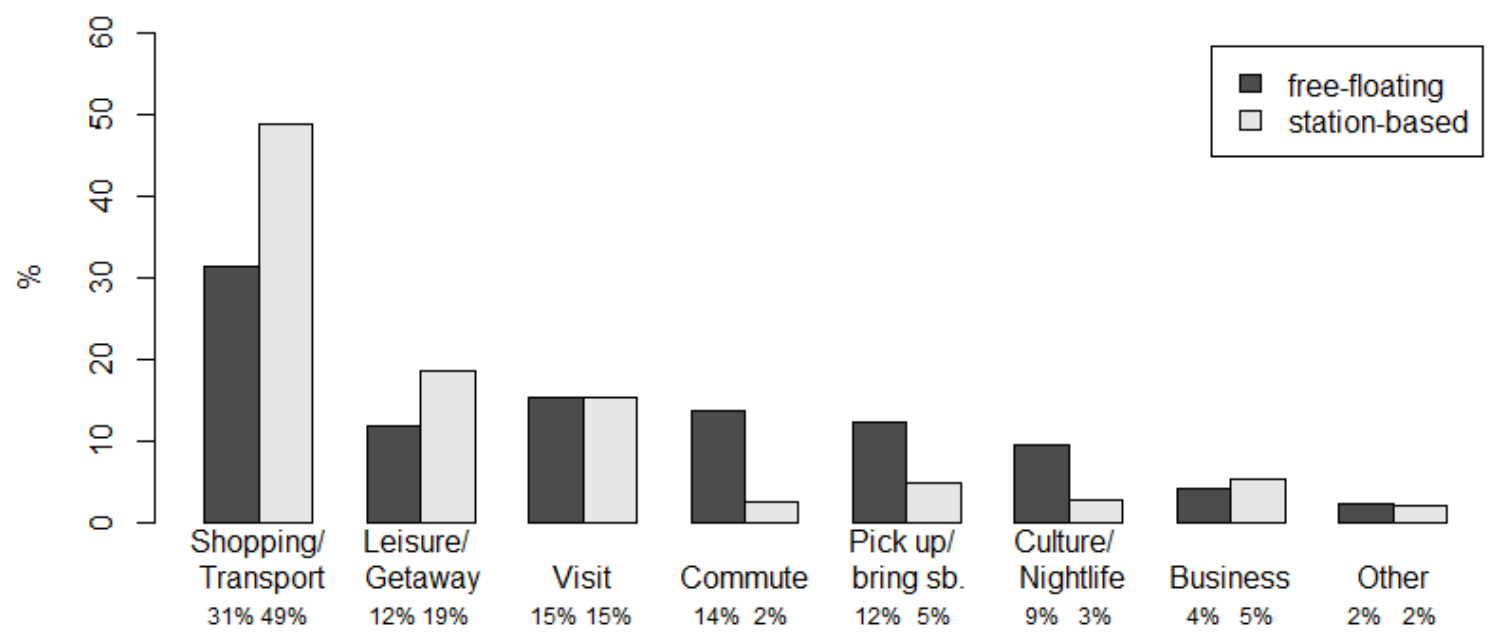

FIGURE 3 Purpose of the last car-sharing ride $\left(N_{\text {free-floating }}=312, N_{\text {station-based }}=571\right)$.

modes or public transportation for most of their trips. Yet, they do not show a significantly different multimodality and even drive longer weekday distances in cars.

\section{How is car-sharing used?}

Due to their distinct design, free-floating and station-based car-sharing can be anticipated to serve different markets. In order to address this issue, car-sharing members were asked to provide details about their most recent car-sharing ride. The results are therefore vaild on the user-level.

As illustrated in Figure 3 , half of the trips undertaken with a station-based car-sharing vehicle $(N=570)$ are shopping trips or trips, for which the customer had large items to carry. In addition, the service is also employed for leisure trips (19\%) and visits (15\%). Other uses turned out to be negligible. In contrast, the free-floating car-sharing service $(N=310)$ is employed for a greater variety of purposes. In particular, there is also substantial usage for commute trips indicating that free-floating car-sharing has the potential to enter the daily trip pattern.

Asked, why they had used car-sharing for their last car-sharing ride, 56\% of the free-floating members stated, that car-sharing was the fastest option. Members of the station-based service, however, cited goods to carry as main reason to use car-sharing (45\%). Indeed, $60 \%$ of the station-based members caried large items on their last car-sharing ride, whereas only $35 \%$ of the free-floating members did so.

Not only are station-based car-sharing vehicles more likely to be loaded with goods, they also have more passengers on board. Whereas $54 \%$ of the free-floating trips $(N=302)$ were conducted by a single driver, $48 \%$ of the station-based cars $(N=550)$ had two people on board. Consequently, the average occupancy is higher for station-based car-sharing (1.99) than for the the free-floating service (1.58).

Moreover, the different nature of the car-sharing services is reflected in the members' 


\section{TABLE 4 Vehicle Ownership Impact}

\begin{tabular}{lrr}
\hline & station-based system & free-floating system \\
\hline no impact & $60.7 \%$ & $54.9 \%$ \\
direct reduction & $25.3 \%$ & $11.8 \%$ \\
indirect reduction & $13.6 \%$ & $30.6 \%$ \\
potential reduction & $0.4 \%$ & $2.8 \%$ \\
\hline
\end{tabular}

planning horizon. Whereas $60 \%$ of the station-based car-sharing members planned their last car-sharing ride at least one day ahead, the same share of free-floating members used the service spontaneously.

The insights from the paragraphs above allow to distinguish the basic usage patterns of the two car-sharing services. Given its specific purposes, large share of transported goods, relatively high occupancy and longer planning horizon, station-based car-sharing is mainly used for trips actually requiring a car such as relocations, shopping, familiy visits or other activities, which can be well planned ahead. In contrast, the shorter planning horizon combined with the lower occupancy and broader range of application indicate, that free-floating car-sharing is used for trips, for which a car is the superior alternative. This may especially apply for tangential routes not well served by transit.

\section{What is its environmental impact?}

Free-floating car-sharing affects its users' daily mobility behaviour by influencing both their tactic (e.g. mode choice) and their strategic (e.g. car-ownership) mobility decisions (33). Since these two levels are intertwined, an assessment of the full effect of free-floating car-sharing has to account for both. Although this can only be done after the second survey wave, the results from this first wave can be used for a qualitative prediction.

As in the case of station-based car-sharing, the net impact of free-floating car-sharing will be determined by its ability to affect strategic mobility decisions and reduce private vehicle ownership (14). Only in this way can the inevitable effect of generating new trips or attracting transit riders be outweighed.

Station-based car-sharing is commonly considered to significantly reduce their members' vehicle-ownership. The findings from this study further support this notion and reveal a similar effect for free-floating car-sharing members. According to the results presented in Table 4 ; one in eight free-floating members $(N=144)$ has either sold or scrapped his car without buying a new one due to the free-floating service (direct impact). Moreover, 30.6\% of the free-floating members report an indirect impact on their car-ownership in that the service allows them to forego the purchase of a (new) car. Another $2.8 \%$ state, that the free-floating car-sharing service lets them consider to sell or scrap their private car (potential impact).

Therefore, free-floating car-sharing can be expected to also reduce vehicle ownership. Although its direct impact is still smaller than the one of the station-based car-sharing service $(N=545)$, the relation may change in future. When interpreting the numbers, one has to bear in mind, that the station-based service has already been around for years, whereas the free-floating service has only been up for at most a few months. 


\section{CONCLUSION}

More than any other kind of car-sharing, free-floating car-sharing relies on public support in order to obtain or extend special parking permissions necessary to operate the system. Due to this direct public involvement, environmental concerns are of particular relevance.

As detailed above, this study allows a direct comparison of free-floating and station-based car-sharing services. By doing so, it contributes to a better understanding of their usage and environmental impact enabling a more qualified public discussion and decision process.

The different nature of station-based car-sharing and free-floating car-sharing was found to address different markets. Although station-based car-sharing was found to have only limited applications, it serves a broader group of users (among the retired or actively working population). In contrast, free-floating car-sharing is employed for a larger variety of purposes including commute trips, which allows the service to enter daily trip chains and therefore to become a viable alternative to a private vehicle. This notion is supported by the result, that free-floating car-sharing members are also more active car-sharers than station-based members, i.e. they use car-sharing more often. Yet, free-floating car-sharing so far has a more restricted user group. Taking into account, that the survey has been conducted shortly after the introduction of the service, the socio-demographic composition of the free-floating car-sharing members may still widen.

Despite apparent differences in user groups and usage patterns, the environmental effect of free-floating car-sharing seems to be comparable to the ones of station-based car-sharing. Members of both schemes report a significantly lower car-ownership level, which they at least partly attribute to their car-sharing membership. Despite that, car-sharing members show a higher than average car travel distance. However, the net effect of free-floating car-sharing can only be estimated after the second survey wave, when its full impact on the members' mobility behaviour can be analyzed.

Methodologically, this study is another successful application of smartphone-based GPStracking as a survey tool. However, data privacy concerns have been found to be a major obstacle for participants. New approaches have to be developed to efficiently build trust among respondents such that the manifold advantages of this new survey system can be fully used. Nevertheless, statistical tests suggest, that the acquired sample data is sufficiently representative for the respective population.

\section{OUTLOOK}

This research is concluded by a second wave of data-taking in fall 2015. Combining the data from the first and the second survey wave will then allow before-and-after comparisons of the respondens' travel behaviour, which will be instrumental to quantify the environmental net effect of free-floating car-sharing.

\section{ACKNOWLEDGEMENT}

This research has been commissioned by Mobility Switzerland and involves a parallel Swiss National Fund (National Research Program 71: Managing Energy Consumption) project. 


\section{REFERENCES}

1. Kopp, J., R. Gerike and K. W. Axhausen (2013) Status Quo and Perspectives for CarSharing Systems: the Example of DriveNow, in R. Gerike, F. Hülsmann and K. Roller (eds.) Strategies for Sustainable Mobilities: Opportunities and Challenges, 207-226, Ashgate, Burlington.

2. Schmöller, S., S. Weikl, J. Müller and K. Bogenberger (2014) Empirical Data Analysis of free-floating carsharing systems, paper presented at the 93rd Annual Meeting of the Transportation Research Board, Washington, D.C., January 2014.

3. Seattle Department of Transportation (2014) 2013 Seattle Free-Floating Car Share Pilot Program Report.

4. Harms, S. and B. Truffer (1998) The emergence of a nationwide carsharing co-operative in Switzerland, Research Report, EAWAG (Eidgenössische Anstalt für Wasserversorgung, Abwasserreinigung und Gewässerschutz).

5. Millard-Ball, A., G. Murray, J. Ter Schure, C. Fox and J. Burkhardt (2005) Car-Sharing: Where and How It Succeeds, Technical Report, 108, TCRP (Transit Cooperative Research Program).

6. Stillwater, T., P. L. Mokhtarian and S. A. Shaheen (2008) Carsharing and the Built Environment, Geographic Information System-Based Study of one U.S. Operator, Transportation Research Record, 2110, 27-34.

7. Grasset, V. and C. Morency (2010) Carsharing: Analyzing the Interaction Between Neighborhood Features and Market Share, paper presented at the 89th Annual Meeting of the Transportation Research Board, Washington, D.C., January 2010.

8. Martin, E. and S. A. Shaheen (2011) The Impact of Carsharing on Public Transit and Non-Motorized Travel: An Exploration of North American Carsharing Survey Data, 4 (11) 2094-2114.

9. Shaheen, S. A., C. Rodier, G. Murray, A. Cohen and E. Martin (2010) Carsharing and public parking policies: assessing benefits, costs, and best practices in North America, Technical Report, CA-MTI-10-2612, Mineta Transportation institute, San Jose, California.

10. Steininger, K., C. Vogl and R. Zettl (1996) Car-sharing organizations - The size of the market segment and revealed change in mobility behavior, Transport Policy, 3 (4) 177-185.

11. Muheim, P. and E. Reinhardt (1999) CarSharing - The Key to Combined Mobility, The Journal of World Transport Policy $\mathcal{E}$ Practice, 5 (3) 58-71.

12. Firnkorn, J. and M. Müller (2011) What will be the environmental effects of new freefloating car-sharing systems? The case of car2go in Ulm, Ecological Economics, 70 (8) 1519-1528.

13. Firnkorn, J. (2012) Triangulation of two methods measuring the impacts of a free-floating carsharing system in Germany, Transportation Research Part A, 46 (10) 1654-1672.

14. Martin, E. and S. A. Shaheen (2011) Greenhouse Gas Emission Impacts of Carsharing in North America, IEEE Transactions on Intelligent Transportation Systems, 12 (4) 10741086. 
15. Le Vine, S., M. Lee-Gosselin, A. Sivakumar and J. Polak (2014) A new approach to predict the market and impacts of round-trip and point-to-point carsharing systems: Case study of London, Transportation Research Part D, 32, 218-229.

16. Le Vine, S., O. Adamou and J. Polak (2014) Predicting new forms of activity/mobility patterns enabled by shared-mobility services through a needs-based stated-response method: Case study of grocery shopping, Transport Policy, 32, 60-68.

17. Ciari, F., M. Balac and M. Balmer (2014) Modeling the effect of different pricing schemes on free-floating carsharing travel demand: a test case study for Zurich, Switzerland, Working Paper, 979, IVT, ETH Zurich, Zurich.

18. Cervero, R., A. Golub and B. Nee (2007) City CarShare: Longer-Term Travel Demand and Car Ownership Impacts, Transportation Research Record, 1992, 70-80.

19. Bricka, S. and C. R. Bhat (2006) A comparative analysis of GPS-based and travel surveybased data, Transportation Research Record, 1972, 9-20.

20. Stopher, P., C. FitzGerald and M. Xu (2007) Assessing the accuracy of the Sydney Household Travel Survey with GPS, Transportation, 34 (6) 723-741.

21. Montini, L., N. Rieser-Schüssler and K. W. Axhausen (2013) Field Report: One-Week GPS-based Travel Survey in the Greater Zurich Area, paper presented at the Swiss Transport Research Conference, Monte Verita.

22. Cottrill, C. D., F. C. Pereira, F. Zhao, I. F. Dias, H. B. Lim, M. E. Ben-Akiva and P. C. Zegras (2013) The Future Mobility Survey: Experiences in developing a smartphone-based travel survey in Singapore, Transportation Research Record, 2354, 59-67.

23. Kopp, J., R. Gerike and K. W. Axhausen (2015) Do sharing people behave differently? An empirical evaluation of the distinctive mobility patterns of free-floating car-sharing members, Transportation, 42, 449-469.

24. Oliveira, M. G. S., P. Vovsha, J. Wolf, Y. Birotker, D. Givon and J. Paasche (2011) Global Positioning System-Assisted Prompted Recall Household Travel Survey to Support Development of Advanced Travel Model in Jerusalem, Israel, Transportation Research Record, 2246, 16-23.

25. Wargelin, L., P. Stopher, J. Minser, K. Tierney, M. Rhindress and S. O'Connor (2012) GPS-Based Household Interview Survey for the Cincinnati Ohio Region, Technical Report, Abt SRBI Inc., New York.

26. Sofistar (2015) Studio Mobilità, www. studio-mobilita.ch:

27. Axhausen, K. W., B. Schmid and C. Weis (2015) Predicting response rates updated, Working Paper, 1063, IVT, ETH Zurich, Zurich.

28. Anderson, T. W. (1962) On the Distribution of the Two-Sample Cramer-von Mises Criterion, The Annals of Mathematical Statistics, 33 (3) 1148-1159.

29. Swiss Federal Statistical Office (BFS) (2012) Mobilität in der Schweiz - Ergebnisse des Mikrozensus Mobilität und Verkehr 2010, Swiss Federal Statistical Office, Neuchatel. 
30. Susilo, Y. and K. W. Axhausen (2007) How firm are you? a study of the stability of individual activity-travel-location patterns using the herfindahl-hirschman index, paper presented at the 11th World Conference of Transport Research, Berkeley, June 2007.

4 31. Hirschman, A. O. (1964) The Paternity of an Index, The American Economic Review, 54 (5) 761.

32. Heckman, J. J. (1979) Sample Selection Bias as a Specification Error, Econometria, 47 (1) 153-161.

33. Le Vine, S. (2011) Strategies for personal mobility: A study of consumer acceptance of subscription drive-it-yourself car services, Ph.D. Thesis, Imperial College London, London. 